\title{
STUDY PENCAHAYAAN ALAMI PADA RUMAH LIMAS PANGGUNG PALEMBANG (Simulasi dengan Program Ecotect 5.0)
}

\author{
Abdul Rachmad Zahrial Amin ${ }^{1}$, Parulian Siregar ${ }^{2}, J_{M}$. Sri Narhadi ${ }^{3}$ \\ Jurusan Arsitektur, Fakultas Sains \& Teknologi, \\ Universitas Katholik Musi Charitas ${ }^{1,2,3)}$, Palembang, Sumatera Selatan \\ E-mail : arach07@gmail.com
}

\begin{abstract}
Sunlight as the largest source of natural light is widely used by humans to carry out their daily activities. Natural light is efficient and saves energy because it does not use electricity. Sometimes humans as light users do not realize how huge the importance of natural light in performing everyday activities as visual comfort. In this study, simulations are conducted on Limas Stilt Houses Palembang. This is due to Limas Stilt Houses has existed since Palembang Sultanate era. This study focuses on research related to the opening on the wall of the elements of these houses through the simulation of natural light. The method used in this research is descriptive analysis method based on engineering and architecture discipline of fields.

From the simulation results obtained that the 'gegajah' space produced very little natural light ranges from 15-30 lux. This is due to gegajah space is located in the middle of the house and just rely on natural light from the 'bengkilas' and 'pawon' rom. While 'bengkilas' and 'pawon' sufficient range of 300-325 lux natural light.
\end{abstract}

Keywords: Natural Light, House Pyramid Stage, Simulation.

\section{PENDAHULUAN}

Pencahayaan alami merupakan pencahayaan tanpa menggunakan energi listrik seperti cahaya buatan yang menggunakan listrik dari Perusahan Listrik Negara (PLN) atapun genset. Bangunan rumah tinggal termasuk dalam jenis bangunan mempunyai tingkat aktifitas penggunaan yang menerus. Aktifitas yang dilakukan secara rutin menuntut derajat kenyamanan yang memenuhi syarat sehingga aktifitas dapat berjalan dengan optimal.

Untuk menjalankan aktifitas secara normal harus mengetahui secara ideal pengukuran derajat kenyamanan terhadap kenyamanan visual sebuah bangunan / ruang ditentukan oleh kuat terang cahaya pada ruangan tersebut. Namun terkadang tidak disadari oleh pengguna bangunan bahwa efek kuat terang cahaya berpengaruh besar terhadap kenyamanan visual yang di implementasikan melalui mata sehingga mengganggu aktifitas dan produktifitas.
Perilaku pengguna ruang terhadap kenyamanan visual dapat terlihat dari prilaku pengguna, misalnya dengan mengerutkan kelopak mata (jika silau) atau membuka mata lebar - lebar (jika ruang terlalu gelap). Penguna ruang dapat beradaptasi dengan menghidupkan lampu atau lebih mencari tempat yang lebih terang.

Kenyamanan visual mata dipengaruhi oleh warna dan cahaya. Mata mengandung sel - sel kerucut (cone sels, unutk siang hari dan mengenali warna) serta sel - sel batang (rod cels, untuk malam hari dan tidak dapat menangkap detail serta warna). Untuk adaptasi mata dari terang ke gelap, sel - sel kerucut membutuhkan waktu 2 menit sedang sel batang membutuhkan waktu 40 menit.

Kenyamanan visual obyek yang dilihat tergantung dari iluminan, ukuran obyek dan Kontras antara obyek dengan sekitarnya. Kontras antara obyek dengan latar belakang perlu tinggi agar obyek mudah dikenali. Setiap $1 \%$ penurunan kontras harus diimbangi $15 \%$ tambahan kekuatan penerangan. Kenyamanan visual dalam 
melakukan aktivitas sehari - hari di dalam rumah bergantung dari jumlah sinar yang masuk ke lokasi mata yang dilihat (misalnya diatas meja) di dalam rumah Limas panggung.

Rumah Limas ini memiliki bukaan jendela yang cukup banyak dan berukuran besar. Untuk itu pencahayaan alami pada rumah limas panggung ini perlu dikaji guna untuk mengetahui pengaruh sistem pencahayaan alami pada rumah panggung terhadap kenyamanan visual mata dalam melakukan aktifitas di dalam rumah. Untuk membuktikan itu dilakukan dengan simulasi ecotect radiance dan menghitung faktor cahaya siang hari (daylight factor) untuk sistem pencahayaan alami.

Cahaya adalah syarat mutlak bagi manusia untuk melihat dunianya. Tanpa cahaya, maka dunia akan gelap, hitam dan mengerikan. Keindahan tidak akan tampak dan dinikmati. Untuk itu manusia membutuhkan cahaya untuk beraktivitas dengan sehat, nyaman dan menyenangkan. Sistem pencahayaan merupakan salah satu faktor yang berpengaruh besar terhadap kenyamanan visual suatu bangunan. Sistem pencahayaan sangat penting diperhatikan pada setiap bangunan guna kenyamanan dalam beraktifitas guna meningkatkan produktifitas dan kenyamanan visual (mata) (Satwiko, hal.85, 2005). Sistem pencahayaan meliputi sistem pencahayaan alami dan sistem pencahayaan buatan. Pencahayaan alami lebih mengutamakan dari sinar matahari yang tentunya dipengaruhi iklim dan kepekatan awan.

Di samping letak dan besaran bukaan jendela juga dipengaruhi oleh besaran bahan penutup jendela (kaca) dan jarak bukaan (jendela) dengan garis terakhir selubung bangunan dan lain - lain. Ruang yang gelap tentunya akan berpengaruh pada kerja mata untuk melihat, begitupun sebaliknya jika terlalu terang / silau membuat mata cepat lelah.

Dengan letak, besaran bukaan jendela yang tidak memenuhi standart memungkinkan aktifitas didalam bangunan terasa kurang nyaman. Maka aspek pencahayaan alami dapat digunakan sebagai salah satu acuan untuk analisa kenyaman visual dalam bangunan. Ada beberapa aspek yang memengaruhi tingkat kenyamanan visual yaitu pencahayaan, warna dan keadaan lingkunan setempat (dinding, bukaan). Dengan desain bukaan jendela yang sesuai, dalam penempatan dan penggunaannya, pencahayaan alami dapat menggantikan pencahayaan buatan dengan demikian mengurangi pemakaian energi dan menghemat biaya.

Ada beberapa kelebihan cahaya dan sinar matahari yaitu bersifat alami (natural), manusia pada dasarnya ingin selalu dekat dengan alam, cahaya matahari memilki nilai - nilai, baik fisik maupun spiritual yang tidak dapat digantikan oleh cahaya buatan, tersedia berlimpah gratis terbarukan (Sinar matahari tidak akan habis hingga matahari mati), memiliki spektrum cahaya lengkap, memiliki daya panas dan kimiawi yang diperlukan bagi makhluk hidup di bumi. Misalnya proses pembentukan pro-vitamin D menjadi vitamin $\mathrm{D}$ dalam tubuh manusia yang membutuhkan bantuan dari sinar matahari pagi. Arah matahari selalu berubah oleh rotasi bumi maupun oleh peredaran bumi terhadap matahari. Selain itu, intensitas cahaya matahari juga berubah - ubah karena adanya halangan awan yang melintas, dapat digunakan untuk terapi (heliotherapy), lebih alami bagi irama tubuh dan keperluan fotografi alami

\subsection{Tinjauan Lokasi}

Kota Palembang berbagi menjadi 2 yaitu Ulu dan Ilir, sedangkan lokas penelitian ini berada di daerah 4 Ulu Palembang tepatnya di rumah bapak Syarifudin. Nama daerah Ulu, dimulai dari 1 (satu) Ulu hingga 16 Ulu yang mengikuti pinggiran Sungai Musi kearah Timur. Kawasan 4 (empat) dan 5 (lima) ulu, dahulunya merupakan daerah perkampungan para pendatang dari Cina dan India, mereka tinggal di sungai (rumah rakit). Sedangkan kaum bangsawan boleh tinggal di darat dengan membangun rumah, yaitu Rumah Limas Panggung. 


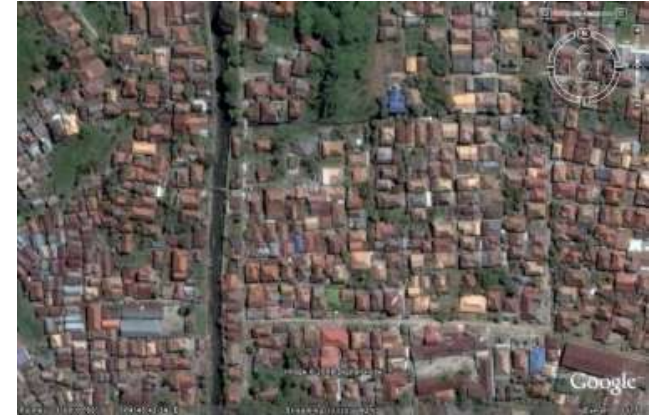

Gambar 1. Peta Kawasan 4-5 Ulu Palembang.

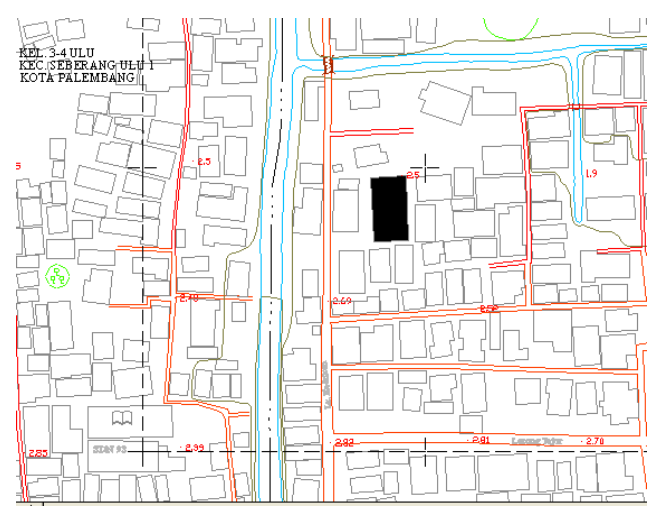

Gambar 2. Peta lokasi penelitian.

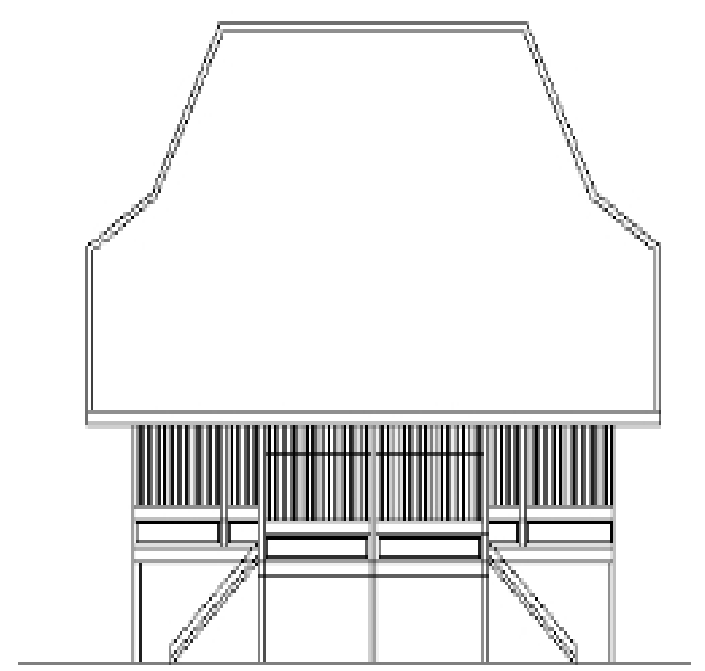

Gambar 3. Tampak depan rumah limas panggung.

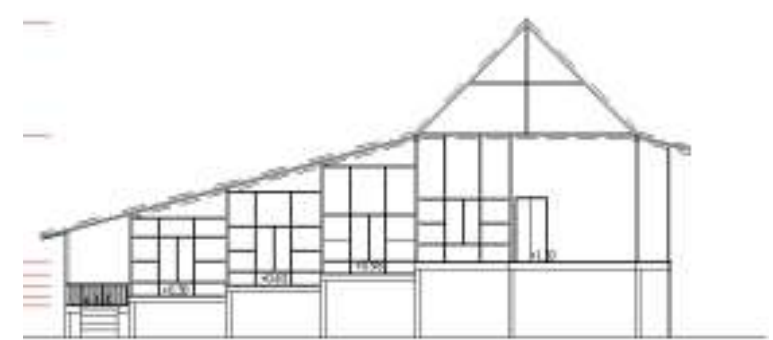

Gambar 4. Tampak samping rumah lima panggung.

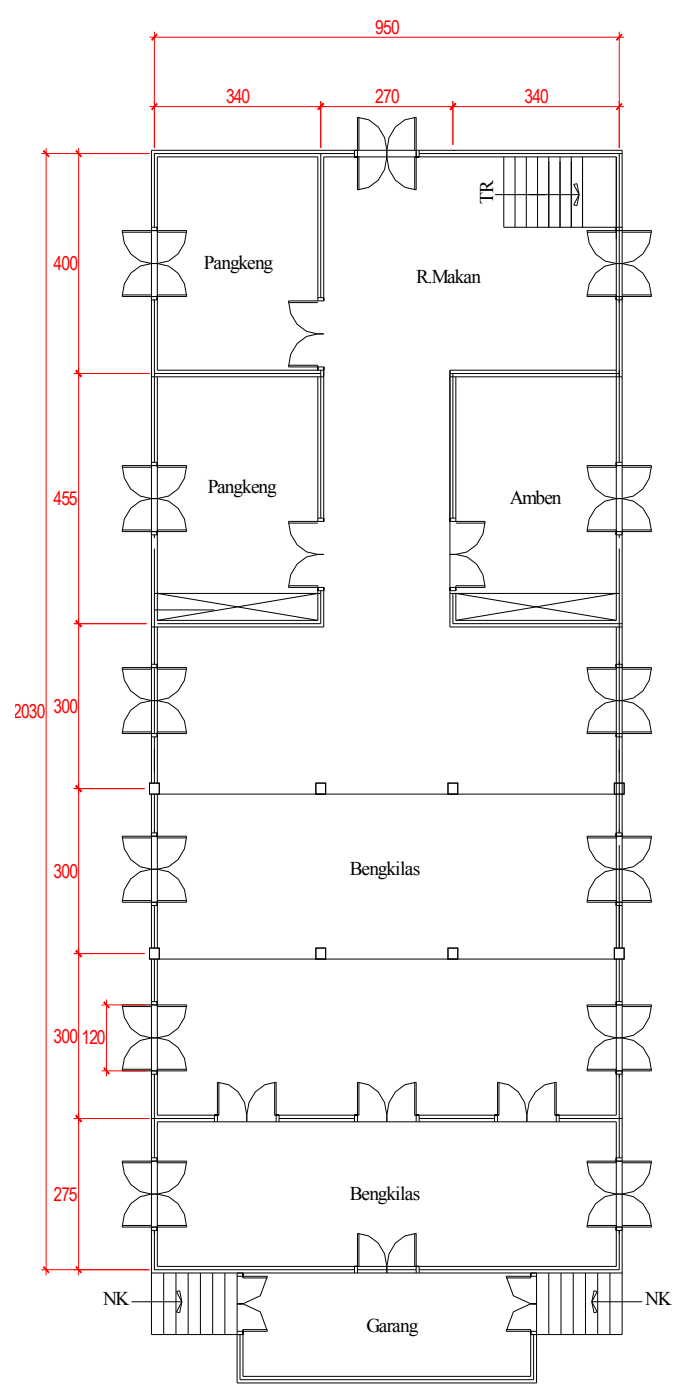

Gambar 5. Denah bangunan rumah limas panggung. 


\section{TINJAUAN PUSTAKA}

\subsection{Sejarah Pencahayaan Alami}

Pada pertengah abad ke XX ketika tersedia cahaya lampu pijar dan murahnya listrik, sejarah pencahayaan alami dan sejarah arsitektur menjadi satu. Dari bentuk arsitektur Roman Groin Vault sampai ke Crystal place dari abad ke-19, perubahan utama struktur merefleksikan tujuan untuk meningkatkan jumlah cahaya yang masuk. Karena pencahayaan buatan tidak terlalu baik dan mahal, bangunan harus memanfaatkan semaksimal mungkin penggunaan cahaya alami.

Pada abad ke 19, semua bangunan kaca menjadi mungkin karena meningkatnya perkembangan cara baru pemakaian besi pada sistem struktur, crystal palace karya Paxton adalah contoh terkenal. Para pakar arsitektur pada abad ke-20 meneruskan penggunaan cahaya alami sebagai kebutuhan fungsional dan dramatis. Le corbusier menciptakan efek sangat dramatis dengan jendela yang terlihat dan menara cahaya pada Kapel Ronchamp. Eero Saarinen menggunakan bentuk dengan cahaya alami paling menarik pada kapel MIT. Skylight diatas altar disesuaikan dengan eggrates hitam sehinga hanya cahaya vertikal yang dapat masuk kedalam Kapel. Cahaya vertikal ini kemudian dipantulkan kedalam ruangan melalui Sclupture yang terbuat dari reflektor kuning seperti daun pohon. Sejarah singkat ini menggambarkan bagaimana pentingnya pancahayaan alami pada dunia arsitektur.

Pencahayaan alami adalah pencahayaan yang bersumber dari matahari dan dari alam (panas lava). Pencahayaan lami menjadi isu kecil arsitektur ketika memasuki abad ke-20 karena tersedianya sumber cahaya buatan yang effisien, murah, banyak dan dapat memenuhi kebutuhan besar pencahayaan buatan.

\subsection{Faktor yang Mempengaruhi Pencahayaan Alami}

Krisis energi pada petengahan 1970-an mengakibatkan adanya peninjauan ulang potensi pencahayaan alami. Pertama, hanya implikasi enrgi yang terkena, tetapi pencahayaan alami juga sangat berharga untuk kemungkinan estetis dan kemapuannya memuaskan kebutuhan biologis.

Pada kebanyakan iklim dan tipe bangunan, pencahayaan alami dapat menghemat energi. Contohnya gedung perkantoran di selatan California dapat menekan pemakaian energi sampai dengan $20 \%$ dengan menggunakan pencahayaan alami. Bangunan seperti kantor, sekolah dan fasilitas industri sering menggunakan 40\% energinya untuk pencahayaan. Ada faktor lain hubungan energi dengan penggunaan pencahayaan alami dan itu merupakan faktor yang lebih penting. Banyak biaya tambahan yang dapat dihemat dapat dialokasikan untuk perancangan ulang sistem pencahayaannya.

Kedinamisan cahaya alami dapat dilihat sebagai kebaikan moral daripada keberlanjutan. Karena hal tersebut terpenuhinya kebutuhan pencahayaan alami secara baik. Perubahan yang lamban, terkadang dramatis dari segi kualitas dan intensitasnya. Bahkan ketika cahaya alami diabaikan, arsitek akan terus menggunakan banyak bukaan jendela untuk mendapatkan pemandangan dan pencahayaan alami yang maksimal.

\subsection{Kealamian Pencahayaan Alami}

Cahaya alami yang masuk melalui jendela dapat berasal dari beberapa sumber, yaitu : sinar matahari, langit cerah, awan atau pantulan permukaan bawah dan bangunan sekitar. Cahaya dari masing masing sumber tersebut bervariasi tidak hanya dari jumlah dan panas yang dibawanya, tetapi kulitas lainnya seperti warna, penyebaran dan penghematan.

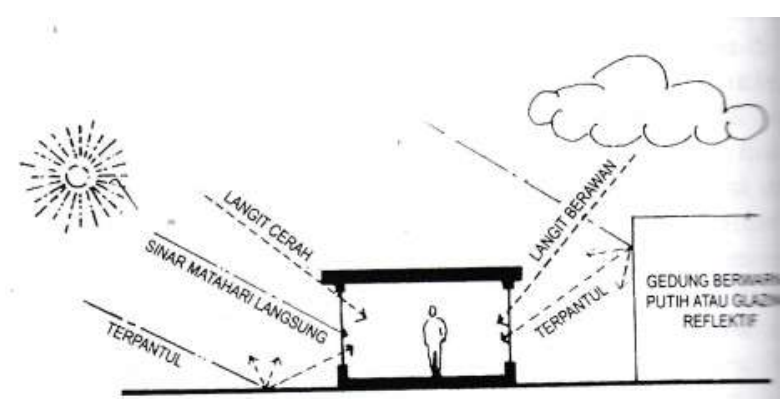

Gambar 6. Beberapa sumber cahaya alami. 
Walaupun kondisi langit berbeda - beda, sangat perlu untuk memahami pencahayaan alami pada dua kondisi yang berbeda : langit mendung dan langit cerah dengan sinar matahari. Distribusi terang cahaya langit yang mendung biasanya tiga kali lebih besar dari pada zenitnya dibanding pada horizonnya. Sedangkan illuminasi dari hari mendung cukup rendah (500-2000 footcandle), masih tetap 10 sampai 15 kali lebih besar dari yang diperlukan diruang dalam. Pada hari yang cerah, bagian langit yang terang merupakan dari arah sinar matahari, sekitar sepuluh kali terang dibandingkan gelapnya yang terjadi sekitar 90 derajat dari matahari.

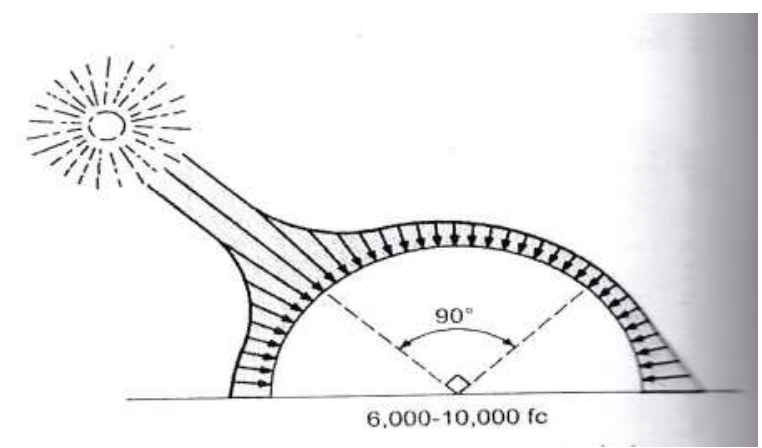

Gambar 7. Distribusi terang cahaya pada hari cerah, bagian langit paling terang yang dekat matahari sepuluh kali lebih terang dari pada bagian gelapnya.

Dibawah langit cerah, illuminasinya cukup tinggi (6000-10000 fc) atau 100-200 kali lebih besar daripada yang dibutuhkan ruang dalam. Pada kondisi tersebut jendela atau skylight dapat berukuran kecil. Kesulitan utama dengan langit cerah adalah tantangan dari sinar matahari langsung, yang tidak selalu terang, tetapi selalu berpindah arah. Akibatnya, untuk memahai illlunimasi hari yang cerah diperlukan juga adanya perubahan harian dan musiman dari matahari.

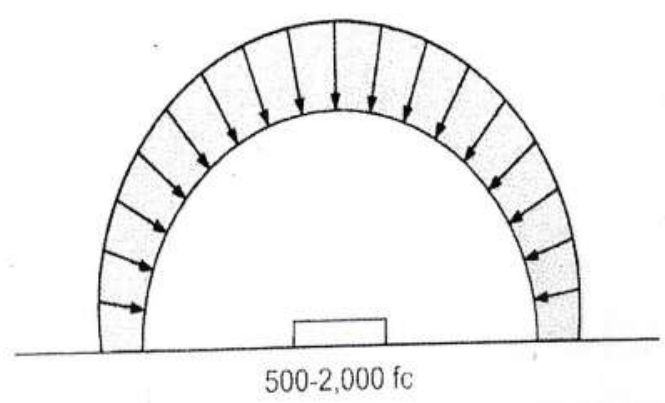

Gambar 8. Distribusi terangnya cahaya dari langit mendung.

\subsection{Tujuan Pencahayaan Alami}

Tujuan pencahayaan alami adalah menghasilkan cahaya berkualitas effisien serta meminimalkan silau, lapisan pemantul dan berlebihnya rasio tingkat terang. Karena keterbatasan lokasi jendela dan variasi cahaya alami, beberapa tujuan spesifik lebih mengacu pada pencahayan alami.

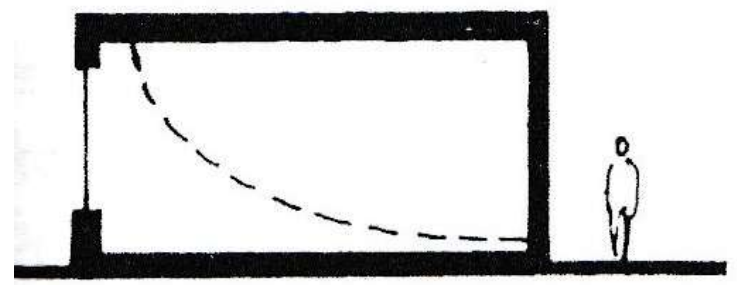

Gambar. 9. Cahaya dari jendela menimbulkan gradien illuminasi yang berlebihan dalam ruang ini warna dekat dinidng belakang terlalu gelap dibandingkan dekat jendela.

Gambar di atas menunjukan sedikitnya pencahayan alami di bagian belakang ruangan dan lebih dari cukup dekat jendela. Jadi tujuan pertamanya adalah mendapatkan cahaya yang masuk lebih dalam kedalam bangunan dengan menaikan tingkat iluminasi dan menurunkan gradien iluminasi yang melewati ruang. 
Tabel 1. Tingkat penerangan

\begin{tabular}{|c|c|c|}
\hline & $\begin{array}{c}\text { Tingkat } \\
\text { Penerangan (lux) }\end{array}$ & $\begin{array}{c}\text { Contoh - contoh Area } \\
\text { Kegiatan }\end{array}$ \\
\hline \multirow{5}{*}{$\begin{array}{l}\text { Pencahayaan Umum untuk } \\
\text { Ruangan dan Area yang } \\
\text { Jarang di Gunakan dan / } \\
\text { atau Tugas - tugas atau } \\
\text { Visual Sederhana }\end{array}$} & 20 & $\begin{array}{l}\text { Layanan penerangan yang } \\
\text { minimum dalam area } \\
\text { sirkulasi luar ruangan, } \\
\text { pertokoan di daerah terbuka, } \\
\text { halaman tempat penyimpanan }\end{array}$ \\
\hline & 50 & $\begin{array}{l}\text { Tempat pejalan kaki dan } \\
\text { panggung }\end{array}$ \\
\hline & 70 & Ruang boiler \\
\hline & 100 & $\begin{array}{l}\text { Halaman trafo, ruang tungku, } \\
\text { dll }\end{array}$ \\
\hline & 150 & $\begin{array}{l}\text { Area sirkulasi di industri, } \\
\text { pertokoan dan } \\
\text { penyimpanan }\end{array}$ \\
\hline \multirow{4}{*}{$\begin{array}{l}\text { Pencahayaan Umum untuk } \\
\text { Interior }\end{array}$} & 200 & $\begin{array}{l}\text { Layanan penerangan yang } \\
\text { minimum dalam tugas }\end{array}$ \\
\hline & 300 & $\begin{array}{l}\text { Meja dan mesin kerja ukuran } \\
\text { sedang, proses umum dalam } \\
\text { industri kimia dan makanan, } \\
\text { kegiatan membaca dan } \\
\text { membuat arsip }\end{array}$ \\
\hline & 450 & $\begin{array}{l}\text { Gantungan baju, } \\
\text { pemeriksaaan, kantor untuk } \\
\text { menggambar, perakitan } \\
\text { mesin dan bagian yang halus, } \\
\text { pekerjaan warna, tugas } \\
\text { menggambar kritis }\end{array}$ \\
\hline & 1500 & $\begin{array}{l}\text { Pekerjaan mesin dan diatas } \\
\text { meja yang sangat halus, } \\
\text { perakitan mesin presisi kecil } \\
\text { dan instrumen ; komponen } \\
\text { elektronik, pengukuran dan } \\
\text { pemeriksaan kecil yang rumit } \\
\text { (sebagian mungkin diberikan } \\
\text { oleh tugas pencahayaan } \\
\text { setempat) }\end{array}$ \\
\hline $\begin{array}{l}\text { Pencahayaan Tambahan } \\
\text { Setempat untuk Tugas } \\
\text { Visual yang Tepat }\end{array}$ & 3000 & $\begin{array}{l}\text { Pekerjaan Berpresisi dan } \\
\text { rinci sekali, misal instrumen } \\
\text { yang sangat kecil, Pembuatan } \\
\text { Jam Tangan, Pengukiran }\end{array}$ \\
\hline
\end{tabular}




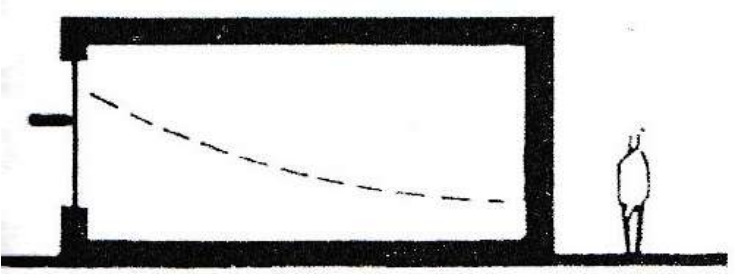

Gambar.10. Salah satu tujuan dari pencahayaan alami adalah menciptakan lebih banyak dapat menerima gradasi iluminasi.

\section{METODE PENELITIAN}

\subsection{Ruang lingkup Penelitian}

Penelitian ini menitik-beratkan pada studi pencahayaan alami di rumah tinggal limas panggung dengan memperhatikan aspek iklim, letak bangunan, arah bangunan serta bukaan jendela. Hasil penelitian ini dibuat dengan menggunakan simulasi program Ecotect radiance 5,0.

\subsection{Metode Pengumpulan Data}

Tahap pelaksanaan dalam penelitian ini meliputi :

\section{Persiapan,}

Mempersiapkan surat ijin survei dan peralatan yang diperlukan, misalnya alat ukur, alat gambar, kamera dan handycam.

2. Pengambilan Data :

a.Data dikumpulkan langsung pada obyek penelitian dari nara sumber dan literatur. Pengambilan data melalui wawancara, pemotretan, pengukuran dan penggambaran.

b.Data yang diperlukan adalah data lapangan berupa ukuran (dimensi) bukaan jendela, kuat terang pencahayaan, ketinggian plafond yang digunakan.

c.Pengukuran di lapangan digunakan untuk menganalisa pencahayaan alami di dalam ruang rumah panggung untuk melakukan simulasi.

\subsection{Metoda Analisa}

Analisa obyektif, analisa ini dilakukan dengan simulasi mengunakan program ecotect radiance untuk mengamati pencahayaan alami melalui contour line. Penelitian ini menitik-beratkan pada kajian yang berkaitan dengan pencahayaan alami melalui elemen bukaan pada dinding rumah panggung. Metode yang dipergunakan dalam penelitian ini adalah metode deskriptif analisis melalui pendekatan teknik Arsitektur.

\subsection{Penelitian Sejenis}

- Optimalisasi Pencahayaan Alami pada Ruang Baca Perpustakaan Studi kasus : sekolah alam madinah school, Jl. Jelupang Utama Raya No.2 Serpong.

- Pemanfaatan Pencahayaan Alami pada Rumah Tinggal tipe town House di Surabaya oleh Purnama Esa Dora, Poppy Firtatwentyna Nilasari, Fakultas Seni dan Desain, Jurusan Desain Interior Universitas Kristen Petra.

\section{HASIL DAN PEMBAHASAN}

\subsection{Denah Rumah Limas}

Pembuatan model ini menggunakan program AutoCad yang difungsikan untuk memperoleh gambaran secara akurat ukuran yang sebenarnya rumah limas panggung serta fungsi ruang-ruang yang ada dalam melakukan aktifitas. Adapun hasil dari penggamabaran dengan autocad berupa gambar denah, tampak depan dan tampak samping.

\subsection{Model Simulasi Ecotect}

Tahap ini merupakan kelanjutan dari tahap sebelumnya, pembuatan model simulasi dibuat secara 3 (tiga) dimensi menggunakan program Ecotect. yang dikondisikan seperti kondisi eksisting, dimulai dari besaran bukaan pintu, dan bukaan jendela yang bertujuan untuk mengetahui seberapa besar cahaya yang masuk kedalam bangunan, sudah sesuia dengan stándar kenyamanan. 


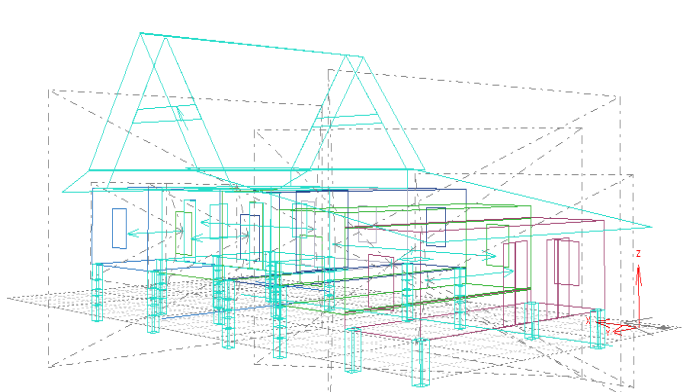

Gambar 11. Kerangka model simulasi dengan ecotect.

\subsection{Input Iklim}

Menginput iklim kota Palembang, agar pada saat menjalankan simulasi mendekati dengan kondisi nyata. Input dilakukan dengan menggunakan load weather file, dan memilih file dalam direktori tempat menyimpan file iklim.

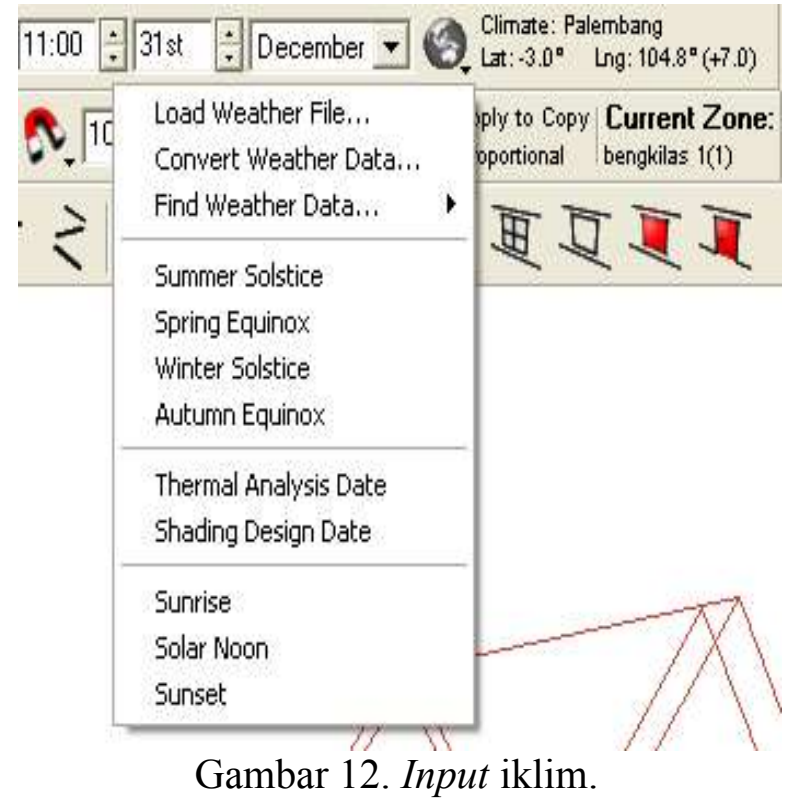

\subsection{Menata Letak Obyek Penelitian}

Menata letak dimaksudkan agar letak obyek penelitian sesuai dengan letak sebenarnya (eksisting) dengan memperhatikan arah utara bumi. Ini akan berkaitan dengan arah lintasan (sun path) matahari sepanjang hari dan sepanjang tahun. Menyesuaikan eksisiting ini dilakukan agar didapat perolehan besaran cahaya alami yang masuk ke dalam bangunan sepanjang hari dan sepanjang tahun.

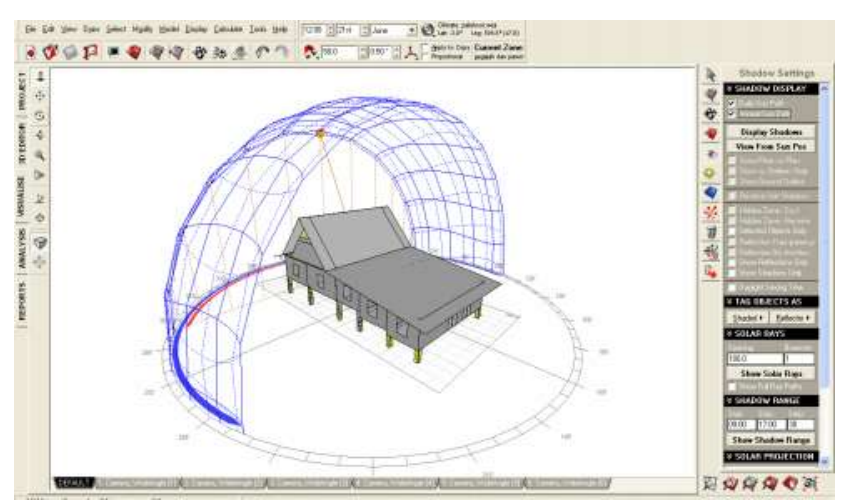

Gambar 13. Lintasan matahari sepanjang tahun pada obyek penelitian.

\subsection{Menjalankan Simulasi}

Pada tahap ini adalah menjalankan simulasi ecotect radiance dengan membuat skenario, bahwa matahari bersinar terbaik pada pukul $08.00-16.00$ wib., (pukul 08.00 wib, 10.00 wib, 12.00 wib, 14.00 wib, dan 16.00 wib) yang berdasarkan lintasan matahari sepanjang tahun, sehingga bulan yang terpilih adalah bulan Maret dan bulan September. Untuk ruang yang diamati adalah ruang yang sering digunakan untuk melakukan aktifitas yaitu ruang bengkilas, gegajah dan pawon.

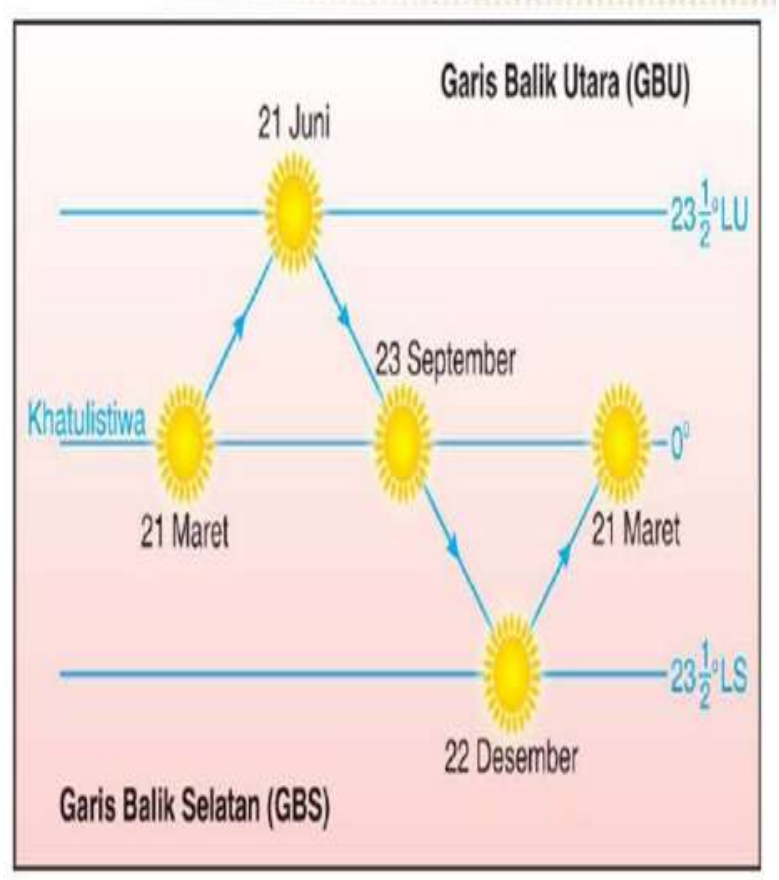

Gambar 14 Lintasan matahari sepanjang tahun. 


\subsubsection{Hasil Simulasi Pembahasan}

\section{Ecotect Radiance}

Tabel 2. Simulasi ruang bengkilas

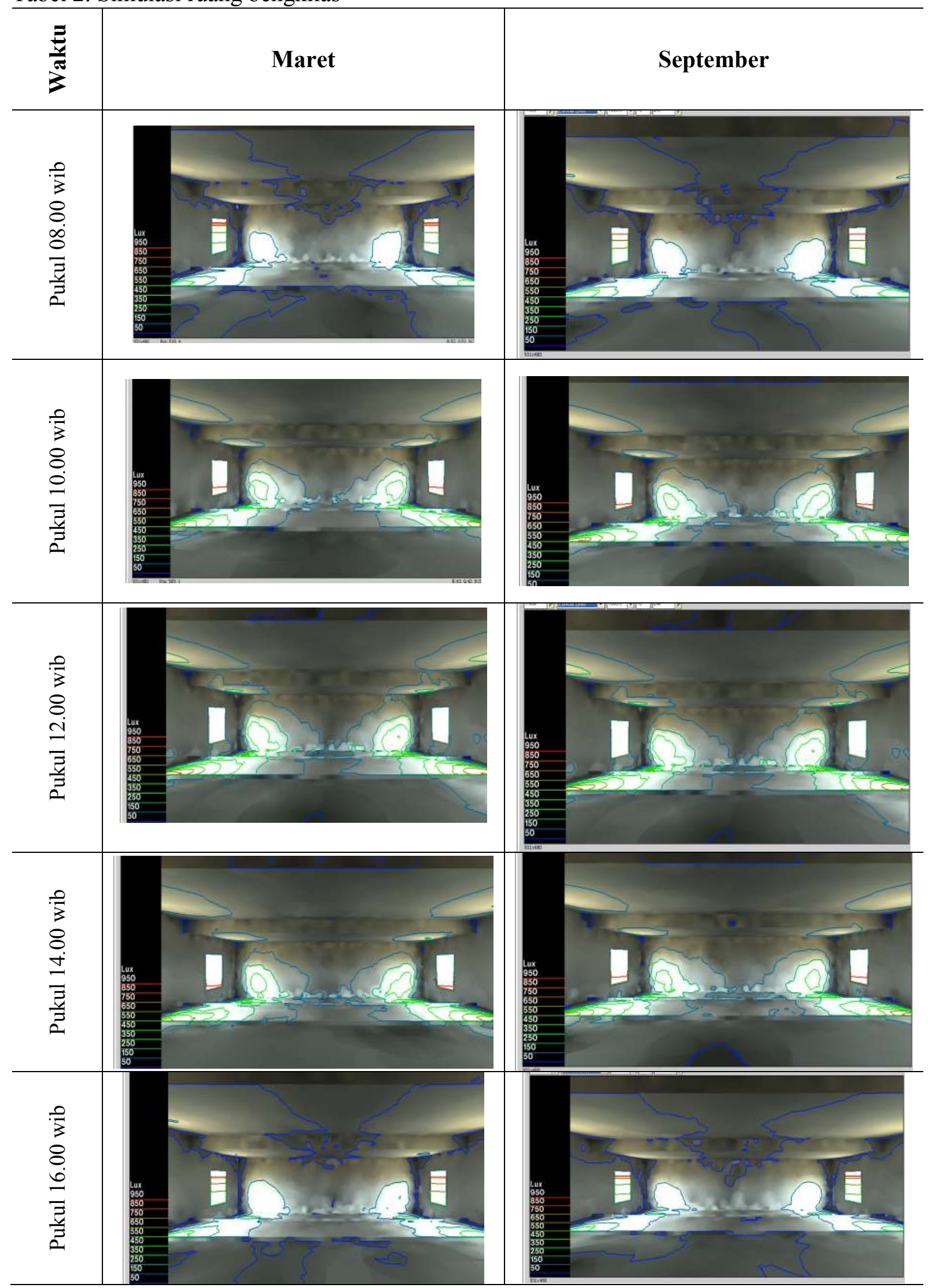


Tabel 3. Simulasi ruang gegajah

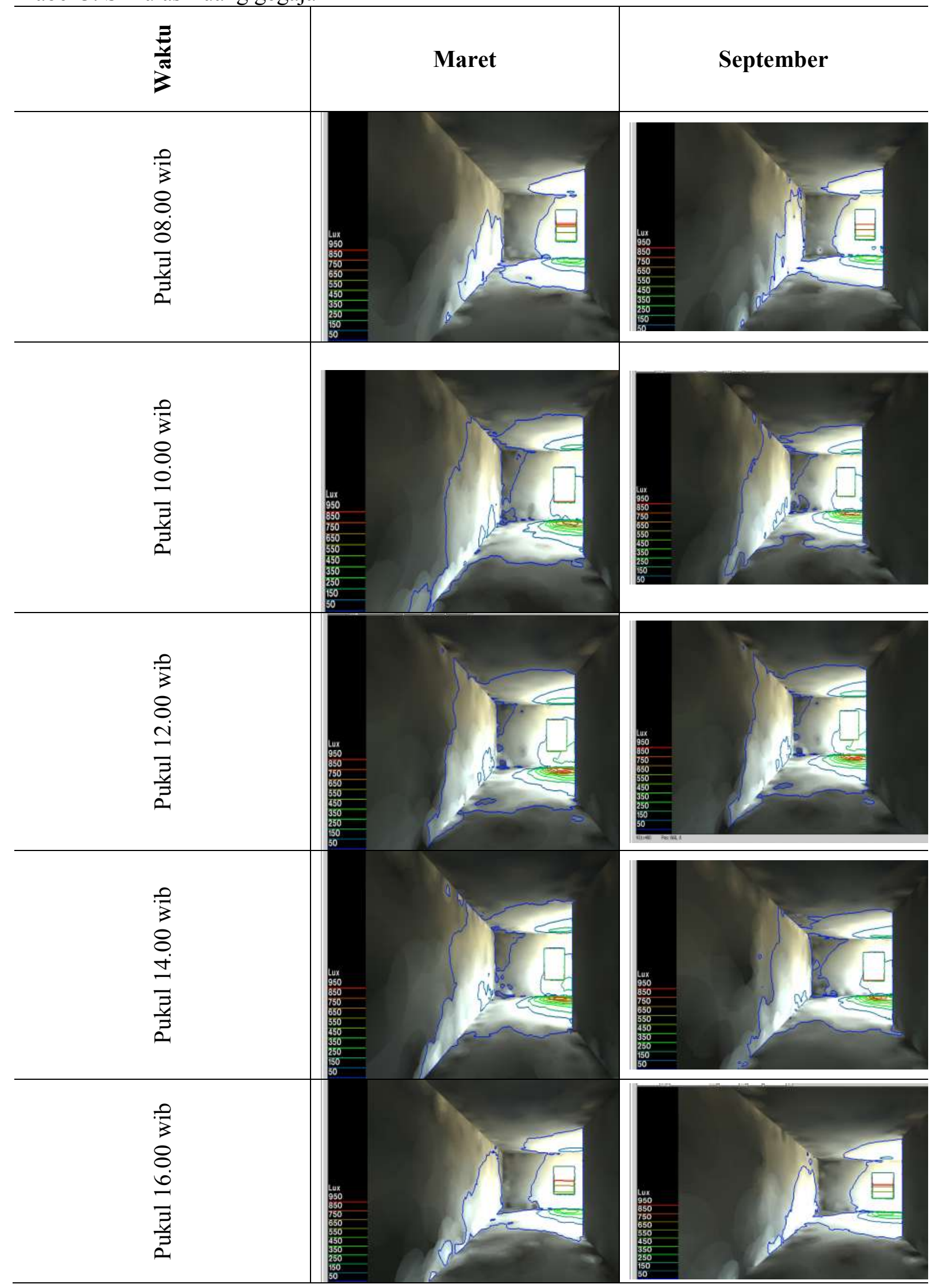


Tabel 4. Simulasi ruang pawon

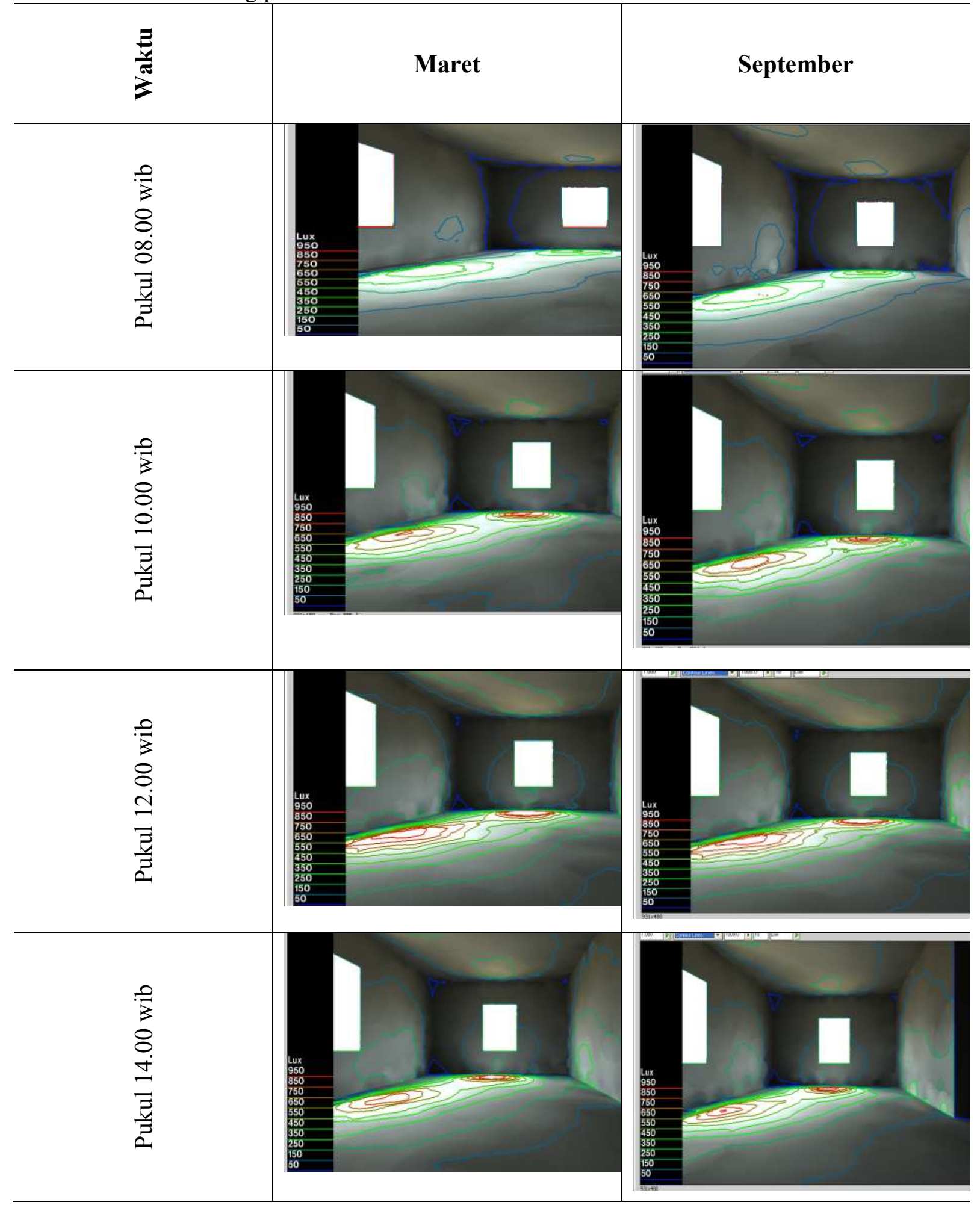




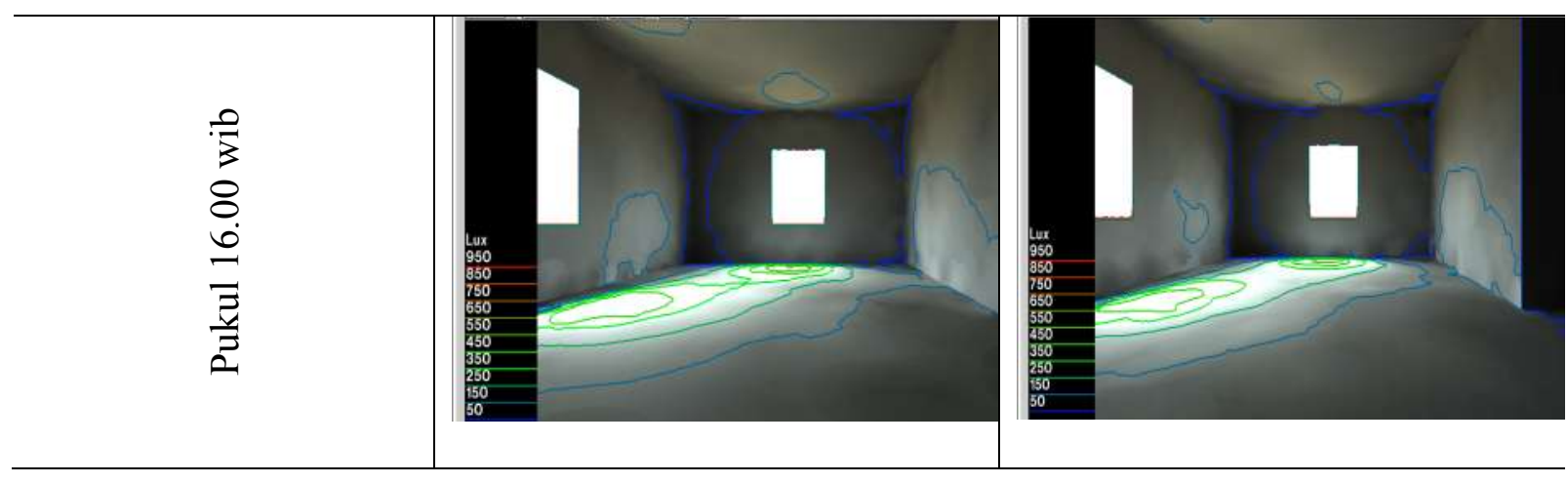

\subsection{Resume}

Mengamati hasil simulasi diatas yang berdasarkan tanggal,waktu (jam) dan bulan , bahwa pencahayaan alami pada : Ruang bengkilas sudah cukup baik $(50-450 \operatorname{lux})$ untuk melakukan aktivitas yang sesuai dengan fungís ruang tersebut, terutama pada pukul 10.00 wib sampai dengan pukul 14.00 wib. Pada ruang pawon dan amben pencahayaan alami sudah cukup baik, terutama pada siang hari pukul 10.00 wib sampai dengan pukul 14.00 wib, ini disebabkan ruang tersebut hanya memiliki dua buah jendela yang berada pada arah barat dan utara. Ruang gegajah ádalah ruang yang paling gelap (9 lux, pada dinding), ini disebabkan karena ruang tersebut berada ditengah bangunan dan hampir tidak memiliki jendela. Pencahayaan alami pada ruang tersebut berasal dari pantulan dari arah depan (ruang bengkilas) dan belakang (pawon).

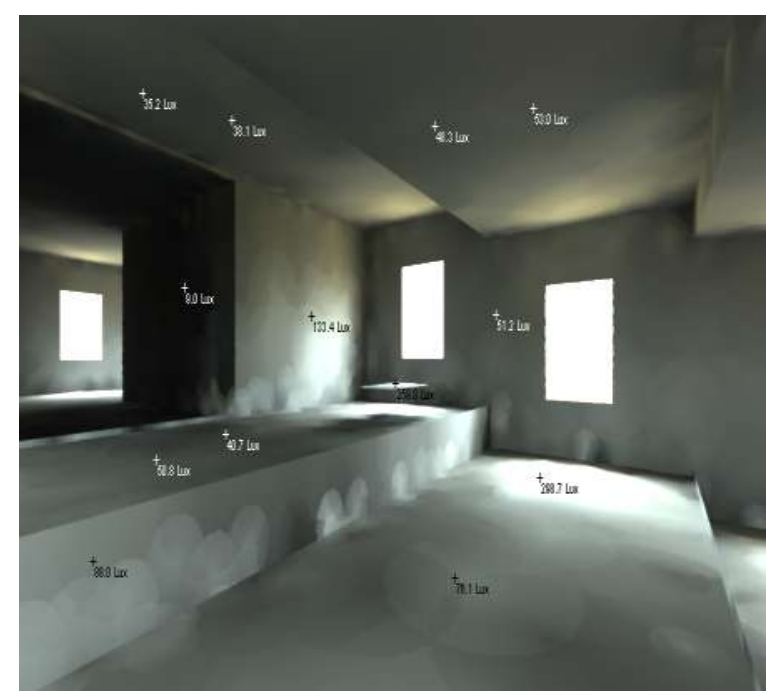

Gambar 15. Kuat terang pada ruang bengkilas dan ruang gegajah.

\subsection{Rencana Tahapan Selanjutnya}

Tahap selanjutnya dapat dilakukan simulasi yang lebih menjurus kepada tempat melakukan aktifitas misalnya melakukan aktifitas menjahit, membaca, belajar dan lain.lain.Ini juga dapat dilakukan dengan simulasi ecotect 5.0 dengan daylight factor agar terlihat jelas value pencahayaan alami yang berada pada tempat aktifitas.

\section{KESIMPULAN DAN SARAN \\ 5.1. Kesimpulan}

Pada simulasi Ecotect Radiance kenyamanan visual ruang bengkilas dapat terlihat bahwa cukup baik dalam melakukan aktifitas seharí - hari, jika diukur pada lokasi dekat jendela 300 lux dan di tengah ruang bengkilas 70 - 90 lux. Ruang pawon juga sangat baik untuk melakukan aktifitas seharihari dengan pencahayaan alami berkisar 330 lux berdasarkan standar nyaman ádalah 300 lux. Sedangkan ruang gegajah sangat tidak nyaman untuk melakukan aktifitas karena kuat terang cahaya 15 - 30 lux, berdasarkan standar ini termasuk ruang sirkulasi berkisar $100 \operatorname{lux}$.

\subsection{Saran}

Diharapkan dilakukan penelitian lebih lanjut tentang pencahayaan rumah limas panggung, dengan simulasi Ecotect Dayligh Factor terhadap adaptasi bangunan rumah limas dengan lingkungan. Dari hasil simulasi ruang Gegajah pencahayaan alami dari segi kenyamanan visual masih kurang dalam melakukan aktifitas sehari - hari, ini dapat menggunakan pencahayaan buatan. 


\section{DAFTAR PUSTAKA}

Breen, ann\& Dick Rigby, 1994, waterfront :

Cities eclaim their Egde, Newyork :

Macgrahill, Inc.

Ecotect 5.5. Tutorial, Autodesk.

Hanafiah, Djohan, 1990, Palembang zaman

Bari : citra Palembang Tempoe

Doeloe, Palembang : Humas Pemda TK II Palembang.

Http://www.palembang.go.id.

Roaf ,Sue , David Crichton and Fergus Nicol, 2005, Dapting Building and cities for climate change, A $21^{\text {st }}$ century survival guide.

Architectural Press.

Satwiko, Prasaato, 2005, Fisika Bangunan jilid 1, Andi Offset.

Satwiko, Prasaato, 2004 Fisika Bangunan jilid 2, Andi Offset.

Standart Nasional Indonesia, 2001 (SNI) 032396.

Www.prodairyfacilities.cornell.edu. 